\title{
Anti-Lipid Peroxidation Activities of Three Selected Fruits Juices Against Cadmium Induced Liver Damage In Vitro
}

Eko Suhartono $^{1 *}$, June Astri Nijka ${ }^{2}$, Vini Yulia Anhar ${ }^{2}$, Rizki Amalia Sari $^{2}$, Edyson $^{1}$, Dona Marisa $^{3}$

\author{
${ }^{1}$ Medical Chemistry and Biochemistry Department, Faculty of Medicine, University of Lambung Mangkurat, Banjarmasin, Indonesia \\ ${ }^{2}$ Faculty of Medicine, University of Lambung Mangkurat, Banjarmasin, Indonesia \\ ${ }^{3}$ Physiology Department, Faculty of Medicine, University of Lambung Mangkurat, Banjarmasin, Indonesia
}

\begin{abstract}
Cadmium $(\mathrm{Cd})$ is one of the most toxic heavy metal. Numerous tissues both in vitro and in vivo suggest that $\mathrm{Cd}$ induced lipid peroxidation. The presence of antioxidant can inhibit this process. This present study was designed to determine the effects of mango, papaya, and banana juices on malondialdehyde levels (MDA) during $\mathrm{Cd}$ exposure in vitro. The result of this study showed that there were a significant difference MDA level between three selected fruits juices. The result of this study also showed the significant differences MDA level between the concentration of each fruit juices. The highest correlation was found between banana juices and MDA levels with IC50 1.12 and followed by papaya and mango juices with IC50 1.37 and 3.87 respectively. The findings of this study suggest that the three selected fruits juices may exert its protective action against Cd-induced lipid peroxidation in liver homogenate in vitro possibly through its antioxidant mechanism.
\end{abstract}

Keywords: antioxidant activity, cadmium, fruits juices, lipid peroxidation

\section{INTRODUCTION}

Cadmium $(\mathrm{Cd})$ is heavy metal that is produced from many industries, such as a battery, electroplating, pigment, plastic, and fertilizer industries [1-2]. Cd contamination and toxicity have become a matter of concern in recent years. Cd has been recognized as one of the most toxic environmental pollutants $[3,4]$. Acute or chronic exposure to $\mathrm{Cd}$ can damage various organs including lung, liver, kidney, bone, testis and placentas $[5,6]$.

It has been well known that the mechanisms responsible for Cd immunotoxicity involved oxidative stress [7]. Oxidative stress is an imbalance between the oxidant and antioxidant. Oxidative stress can cause damage to macromolecules such as lipids and called lipid peroxidation [8-9].

Lipid peroxidation is characterized by some complex compounds formation including reactive carbonyl compounds, such as MDA [10]. MDA has been found to play a major role in the toxicity of $\mathrm{Cd}$ [11]. Previous

\footnotetext{
${ }^{*}$ Corresponding author:

Eko Suhartono

Medical Chemistry and Biochemistry,

Faculty of Medicine, University of Lambung Mangkurat,

Banjarmasin-Indonesia

E-mail: ekoantioxidant@gmail.com
}

studies showed that there were significant differences in kidney MDA levels between control and Cd treatment groups [12]. Other previous studies also revealed that Cd exposure increase the level of MDA. MDA levels were increased with the increasing of time exposure and Cd concentration [13].

South Kalimantan is one of the areas in Indonesia that has a variety of fruits [14-15]. It is well known that the fruits are good for health. It is because the fruits contained compounds that act as an antioxidants [16-18]. Antioxidants can terminate or retard the oxidation process, as well as lipid peroxidation [19-20].

However, effects of these three selected fruits juices (bananas, mango, and papaya), as an inhibitor of lipid peroxidation induced by $\mathrm{Cd}$ have not yet been studied. Therefore, the aim of this study was to investigate the anti-lipid peroxidation of Musa acuminata, Carica papaya and Mangifera indica juices against cadmium-induced lipid peroxidation in vitro.

\section{MATERIALS AND METHODS \\ Chemical and Materials}

Phosphate buffer saline, $\mathrm{CdSO}_{4}$, SDS (sodium dodecyl sulfate), acetic acid, TBA (thiobarbituric acid) solution, N-butanol, pyridine were from Sigma. 


\section{Fruit Materials}

Three types of tropical fruits and used as reference were studied. They were Mauli bananas (Musa acuminata), Papaya (Carica papaya), and Mangga (Mangifera indica). The fresh fruits species were procured from the local market for the present study.

\section{Juice Preparation}

The fruits were separated carefully from the skin and seeds. Then the juice was made with the help of juicer. The fresh juice was used for all investigations. The juice was extracted from the homogenized flesh of the fruits of each cultivar. The juice was separated from the pulp by pressing it several times and centrifuging it at $1500 \times \mathrm{g}$ for $20 \mathrm{~min}$. The supernatant juice was filtered and kept at $4^{\circ} \mathrm{C}$ until use.

\section{Experimental Section}

Male albino rats (Rattus novergicus) weighing 200$259 \mathrm{~g}$, were used in this study. All rats were caged separately for acclimation period for one week. During the acclimation period, the rats were drink and fed with the same waters and food. PDAM water as drinking water and C-05 pellets as foods. The rats were fasted for 1-2 hours to ensure that the rat stomach empty before treatment. Ethical clearance was obtained from the faculty of medicine, Lambung Mangkurat University, South Kalimantan, Indonesia.

Then the animals were sacrificed by a surgical procedure with ether as an anesthesia. The abdomen was opened; the liver was removed and then homogenized in phosphate buffer saline ( $\mathrm{pH}$ 7.0). Then $1 \mathrm{ml}$ liver homogenate $(10 \% \mathrm{w} / \mathrm{v})$ was added to test juices of different concentrations.

\section{Anti-Lipid Peroxidation Assay}

The lipid peroxidation was initiated by adding the $\mathrm{CdSO}_{4}$ solution to the liver homogenate, and then the fruits juices in different concentrations were added. Then the MDA levels were measured by the modified method of Ohkawa et al. and Masao et al. [21]. The percentage of MDA formation inhibition was calculated using the formula:

Percentage Inhibition $=($ Abs control-Abs sample $) \mathrm{x}$ 100 / Abs control.

Abs control: Blank solution absorbance that contained liver homogenate and $\mathrm{CdSO}_{4}$ solution.

Abs sample: Solution absorbance that contained liver homogenate and $\mathrm{CdSO}_{4}$ solution with the fruits juices.

\section{Statistical Analysis}

The results are expressed as the mean $\pm \mathrm{SD}$ for three triplicates. Linear regression analysis as used to calculate IC50 value.

Kruskal-Wallis test evaluated the difference of MDA formation inhibition between three selected fruits and between concentration. All data were entered into and processed by SPSS 17,0 for Windows.

\section{RESULTS AND DISCUSSION}

Several concentrations of the three selected juices fruits were tested for their anti-lipid peroxidation activity induced by $\mathrm{CdSO}_{4}$ in the liver homogenate. The result showed in figure $1 \mathrm{~A}, \mathrm{~B}$, and $\mathrm{C}$.

Figure $1 \mathrm{~A}, \mathrm{~B}$, and $\mathrm{C}$ shows the inhibition effect of three selected fruits on MDA formation. Kruskal-Wallis test result that there are significance differences in MDA formation among the three selected fruits and the three concentration $(p<0,05)$. It means the three selected, and the concentration of fruits juices affect the MDA formation during Cd exposure.

The $\mathrm{Cd}$ is a toxic metal that may induce oxidative damage by disturbing the balance of prooxidant-antioxidant in the tissues [1]. One of oxidative damage indicator by $\mathrm{Cd}$ is the accumulation of MDA, which is a breakdown product of lipid peroxidation [22].

The Cd is unable to generate free radicals itself, but somehow $\mathrm{Cd}$ could generate the free radicals indirectly. The Cd could generate free radicals via the Fenton chemistry. Cadmium could replace other metals such as, iron and copper, which in turn to release and increase the concentration of unbound iron or copper ions. These free ions participate in causing oxidative stress via the Fenton reactions. Recently, Watjen and Beyersmann showed evidence in support of the proposed mechanism [23].

Also, cadmium was shown to inhibit complex III of the mitochondrial respiratory chain. The inhibition of complex III would lead to the accumulation of semi ubiquinones and the formation of radical superoxide [24].

Another mechanism how is $\mathrm{Cd}$ could generate the formation of free radicals were disturbing the cellular antioxidant and induced the formation of pro-inflammatory cytokines [24-25].

These excessive of ROS production by a several mechanism, as mentioned above can promote the lipid peroxidation process. The first step of lipid peroxidation process called initiation. First, a hydrogen atom from a methylene group in the lipid was abstracted. Then, the presence of a double bond adjacent from the 

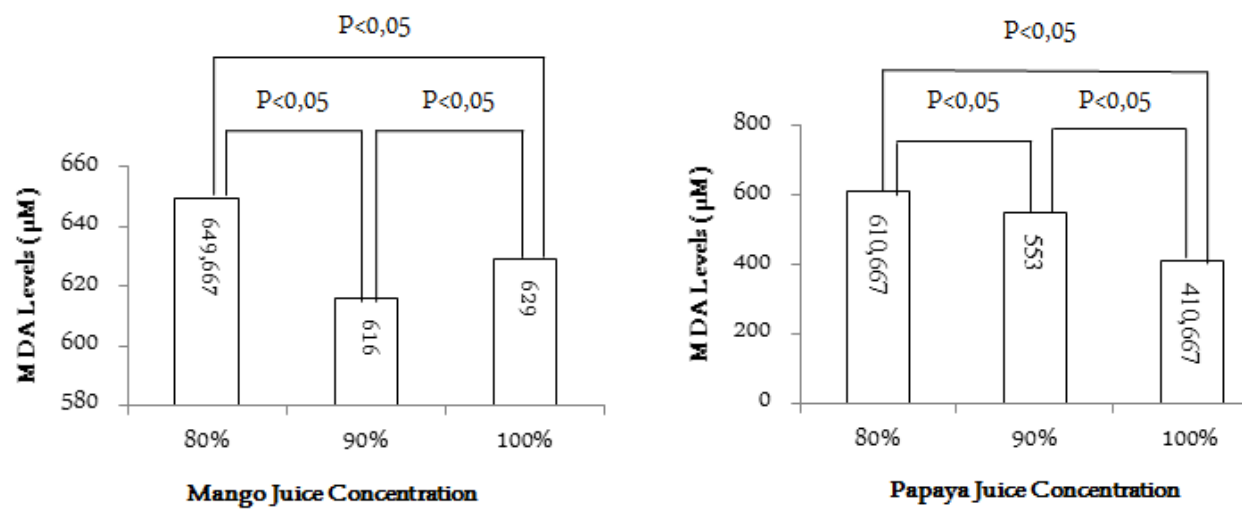

A

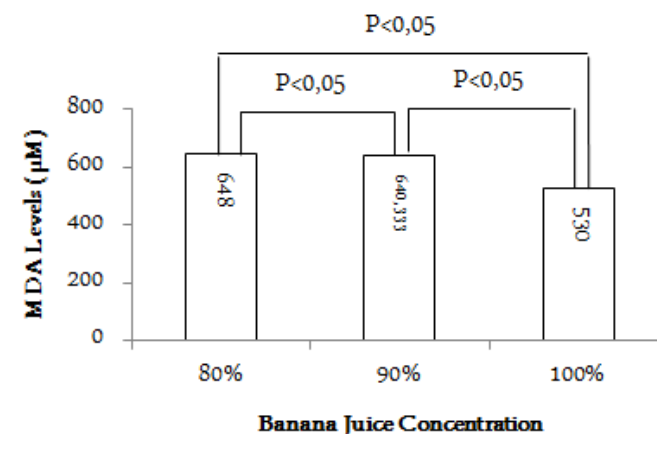

C

Figure 1. Inhibition effects of (A)Mango; (B)Papaya; (C)Banana juices on MDA formation. Value are expressed as mean \pm SD. Statis tical significance of difference among groups of treatment at $\mathrm{p}<0,05$ using Kruskal-Wallis test.

methylene group weakens the bond between carbon and hydrogen. Further, the hydrogen removed from the fatty acid molecule [25-26].

The initiation process resulted in a fatty acid having one unpaired electron. When oxygen is present in the tissues, the fatty acid from the initiation process can react with it and lead to the formation of lipo-peroxyl radicals $(\mathrm{ROO} \bullet)$. $\mathrm{ROO} \bullet$ can be rearranged via a cyclization reaction to endoperoxides with the final product of peroxidation process being MDA [27].

The presence of fruits juices can inhibit the MDA formation chain reaction. To analyzed the correlation between the presence of fruits juices and MDA levels, linear correlation regression analysis was used. The highest correlation was given by banana $(0,97)$ juices, followed by papaya $(0,89)$ and mango $(0,67)$ juices (Table 1).

To compared which of these three selected juices fruits are most effective to inhibit the MDA formation during the exposure of Cd, IC50 between these selected fruits juices was evaluated. The IC50 value for each fruit juices, defined as the concentration of extract causing 50 percent inhibition of MDA formation. The Lower IC50 value indicates higher anti-lipid peroxidation inhibition activity. Table 1 showed that the most effective is banana juices, followed by papaya and mango.

According to the results, all three selected fruits juices has anti-lipid peroxidation activity. The anti-lipid peroxidation activities of three selected fruits juices has been attributed to the presence of antioxidants, such as flavonoids, and vitamins like ascorbic acid (vitamins C), tocopherol (vitamin E) and $\beta$-carotene [28].

Previous studies showed that these three selected fruit contain phenolic compound [29]. Anti-lipid peroxidation action of phenolic compounds is due to their high tendency to chelate metals. Phenolics possess hydroxyl and carboxyl groups, able to bind iron and copper particularly. Also, the phenolic compounds may inactivate iron ions by chelating and additionally suppressing the superoxide-driven Fenton reaction [30]. Another mechanism how phenolic compounds could 
Table 1. Percentage of MDA formation inhibition activity of three selected fruits

\begin{tabular}{cccc}
\hline \multirow{2}{*}{ Concentration } & \multicolumn{3}{c}{ MDA Formation Inhibition (\%) } \\
\cline { 2 - 4 } & Mango & Banana & Papaya \\
\hline $80 \%$ & $0,00 \pm 0,00$ & $0,00 \pm 0,00$ & $0,00 \pm 0,00$ \\
$90 \%$ & $5,18 \pm 0,21$ & $1,18 \pm 0,07$ & $9,44 \pm 0,29$ \\
$100 \%$ & $3,18 \pm 0,14$ & $18,21 \pm 0,03$ & $0,00 \pm 0,00$ \\
$\mathrm{R}^{2}$ & 0,37 & 0,94 & 0,80 \\
$\mathrm{r}$ & 0,61 & 0,97 & 0,89 \\
IC50 (\%) & 3,87 & 1,12 & 1,37 \\
\hline
\end{tabular}

reduced the lipid peroxidation becomes hydrogen donors and singlet oxygen quenchers. From this mechanism, phenolic can play a significant role in absorbing and neutralizing free radicals [31].

Another phytochemical constituents in theses, three selected fruits juices are ascorbic acid. According to Rekha et al. [33], ascorbic acid acts as a particular antioxidant by reducing ferric ions, this could reduced lipid peroxidation. Also, ascorbic acid could transfer the hydrogen atoms to oxygen. From this mechanism, ascorbic acid make the levels of oxygen are reduced, so the reactive oxygen chain reaction also reduced [32,33].

Tropical fruits such as these three selected fruits in the experimental model also appear to be good sources of carotenoid [34]. Carotenoids principalls scavenge two types of ROS: singlet molecular oxygen and peroxyl radicals. They deactivate effectively the electronically excited sensitizer molecules, which are involved in the generation of radicals and singlet oxygen [35]. Carotenoid also can bind with lipid peroxyl radical resulting in the formation of a carbon-centered radical, it would interfere the propagating step in lipid peroxidation [36].

\section{CONCLUSIONS}

The present in vitro studies found that banana juices demonstrated the highest anti-lipid peroxidation activity during $\mathrm{Cd}$ exposure and followed by papaya and mango juices. According to biological in vitro assays, certain unknown compounds in these three selected juices may play significant roles as an inhibitor of lipid peroxidation. Overall, the three selected juices could be regarded as a potential anti-lipid peroxidation agent, especially in $\mathrm{Cd}$ intoxication. Further investigation of the health benefits using in vivo and human study are required.

\section{ACKNOWLEDGMENT}

Authors are thankful to Iskandar, dr. from Research Unit Mutiara Bunda Mother and Child Hospital, Martapura South Kalimantan Indonesian, for his support and encouragement during the process of writing this research.

\section{REFERENCES}

1. Ognjanovic BI, Markovic SD, Pavlovic SZ, Zikic RV, Stajn AS, Saicic ZS (2008) Effect of Chronic Cadmium Exposure on Antioxidant Defense System in Some Tissues of Rats: Protective Effect of Selenium. Physiol. Res. 57: 403-411.

2. Adjar W, Rahaju FA, Firdaus RT, Suhartono E (2014) The role of urinary cadmium and lead level on pregnant women renal function. JOMB. 3(1): 55-58.

3. Kant V, Mehta M, Varshneya C, Shivani C (2011) Induction of Oxidative Stress by Subacute Oral Exposure of Cadmium Sulphate in Adult Poultry. Braz J Vet Pathol. 4(2): 117-121.

4. Husna AH, Ramadhani EA, Eva DT, Yulita AF, Suhartono E (2014) The role formation of methylglyoxal, carbonyl compound, hydrogen peroxide and advance oxidation protein product induced cadmium in ovarian rat. IJCEA. 5(4): 319-323.

5. Gonick HC (2008) Nephrotoxicity of cadmium and lead. Indian J Med Res. 128 (00): 335-352.

6. E. Suhartono, Triawanti, A.S. Leksono, M.S. Djati (2014) The role of cadmium in protein glycation by glucose: formation of methylglyoxal and hydrogen peroxide in vitro. JOMB. Vol. 3, no. 1, pp. 59-62.

7. Shi-Wen X, Xiao-Long W, Jin-Long L, Hui-Xin L, Shu Li, Zhao-Xin T (2010) Oxidative Stress-Mediated Cytotoxicity of Cadmium in Chicken Splenic Lymphocytes. Polish J. of Environ. Stud. 19(5): 947-956.

8. Noori S, Mahboob T (2010) Antioxidant effect of carnosine pretreatment on cisplatin-induced renal oxidative stress in rats. IJCB. 25(1): 86-91.

9. Ahmed AM (2012) Lipid Peroxidation and Oxidative Protein Products as Biomarkers of Oxidative Stress in the $\mathrm{Au}$ togenous Mosquito, Aedes caspius, Upon Infection with the Mosquitocidal Bacterium, Bacillus thuringiensis kurstaki. Pakistan. J Zool. 44(2): 525-536.

10. Maryanto S (2013) The effects of red guava (Psidium guajava L) fruits on lipid peroxidation in hypercholesterolemic rats. Basic Res. J. Med. Clin. Sci. 2(11): 116-121.

11. Suhartono E, Triawanti, Yunanto A, Firdaus RT, and Iskandar (2013) Chronic cadmium hepatooxidative in rats: Treatment with Haruan fish (Channa striata) extract. APCBEE Procedia. 5: 441-445.

12. Suhartono E, Triawanti, Leksono AS, Djati MS (2014) 
Oxidative Stress and Kidney Glycation in Rats Exposed Cadmium. IJCEA. 5(6): 497-501.

13. Aflanie I, Muhyi R, Suhartono E (2015) Effect of heavy metal on Malondialdehyde and advanced oxidation protein products concentration: A focus on arsenic, cadmium and mercury. JOMB. 4(4): 332-337.

14. Tanjung E, Muhammad Hafidz MS, Iskandar, Suhartono E (2014) Evaluation of antioxidant activity of some selected fruits in South Kalimantan, Indonesia. J. Trop. Life. Science. 4(3): 210-215.

15. Suhartono E, Viani E, Rahmadhan MA, Gultom IS, Rakhman MF, Indrawardhana D (2012) Total flavonoid and antioxidant activity of some selected medicinal plants in South Kalimantan of Indonesian. APCBEE Procedia. 4: 235-239.

16. Mohapatra D, Mishra S, Namrata S (2010) Banana and its by-product utilisation: an overview. J Sci Ind Res. 69: 323329.

17. Ma X, Wu H, Liu L, Yao Q, Wang S, Zhan R, Xing S, Zhou Y (2011) Polyphenolic compounds and antioxidant properties in mango fruits. J. Scienta. 129: 102-107.

18. Ozkan A, Gubbuk H, Gunes E, Erdogan A (2011) Antioxidant capacity of juice from different papaya (Carica papaya L.) cultivars grown under greenhouse conditions in Turkey. Turk. J. Biol. 35: 619-625.

19. Mandal P, Misra TK, Ghosal M (2009) Free-radical scavenging activity and phytochemichal analysis in the leaf and stem of Drymaria diandra blume. IJIB. 7(2): 80-84.

20. Fu L, Bo-Tao X, Xiang-Rong X, Xin-Sheng Q, Ren-You G, Hua-Bin L (2010) Antioxidant Capacities and Total Phenolic Contents of 56 Wild Fruits from South China. Molecules. 15: 8602-8617.

21. Sakat SS, Juvekar AR, Gambhire MN (2010) In vitro antioxidant and anti-inflammatory activity of methanol extract of Oxalis corniculata linn. J. Pharm. Pharm. Sci. 2(1): 146-155.

22. Liu Z, Chen W, He X (2011) Cadmium-induced changes in growth and antioxidative mechanisms of a medicine plant (Lonicera japonica Thunb.). J. Med. Plant. Res. 5(8): 1411-1417.

23. Flora SJS (2009) Metal poisoning: threat and management. Al Ameen. J Med Sci. 2(2): 4-26.

24. Henkler F, Brinkmann J, Luch A (2010) The Role of Oxidative Stress in Carcinogenesis Induced by Metals and Xenobiotics. Cancers. 2: 376-396.

25. Arroyo VS, Flores KM, Ortiz LB, Gómez-Quiroz LE,
Gutiérrez-Ruiz MC (2012) Liver and Cadmium Toxicity J. Drug. Metab. Toxicol. S5(001): 1-7.

26. Repetto M, Semprine J, Boveris A (2012) Lipid Peroxidation: Chemical Mechanism, Biological Implications and Analytical Determination. General and Inorganic Biochemistry Chapter 1. http://dx.doi.org/10.5772/45943.

27. Gill SS, Tuteja N (2010) Reactive oxygen species and antioxidant machinery in abiotic stress tolerance in crop plants. Plant. Physiol. Bioch. 48: 909-930.

28. Adefegha SA and Oboh G (2011) Water Extractable Phytochemicals from Some Nigerian Spices Inhibit $\mathrm{Fe}^{2+}-\mathrm{In}$ duced Lipid Peroxidation in Rat's Brain - In Vitro. J. Food. Process. Technol. 2(1): 1-6.

29. Patthamakanokporn O, Puwastien P (2008) Changes of antioxidant activity and total phenolic compounds during storage of selected fruits. J. Food. Compost. Anal. 21: 241248.

30. Michalak A (2006) Phenolic compounds and their antioxidant activity in plants growing under heavy metal stress. Polish. J. Of Environ. Stud. 15(4): 523-530.

31. Adithya ES, Lakshmi MS, Christabel PH, Sasikumar JM (2013) In vitro antioxidant, anti-lipid peroxidation activities and HPLC analysis of methanol extracts from bark and stem of Mahonia leschenaultia takeda. Asian J. Plant. Sci. Res. 3(2): 116-126.

32. Kamruzzaman AK, Mahfuza M, Afzal IH, Arzina H, Roksana H (2014) A comparison with antioxidant and functional properties among five mango (Mangifera indica L.) varieties in Bangladesh. IFRJ. 21(4): 1501-1506.

33. Rekha C, Poornima G, Manasa M, Abhipsa V, Devi JP, Kumar HTV, Kekuda TRP (2012) Ascorbic acid, total phenol content and antioxidant activity of fresh juices of four ripe and unripe citrus fruits. Chem Sci Trans. 1: 303310.

34. Khoo HE, Prasad KN, Kong KW, Jiang Y, Ismail A (2011) Carotenoids and Their Isomers: Color Pigments in Fruits and Vegetables. Molecules. 16: 1711-1738.

35. Rodriguez-Amaya DB (2010) Quantitative analysis, in vitro assessment of bioavailability and antioxidant activity of food carotenoids-A review. J. Food. Compost. Anal. 23: 726-740.

36. Karppi J (2011) Measurements of carotenoids and their role in lipid oxidation and cancer. Publications of The University of Eastern Finland. Dissertation in Health Sciences. 43: 1-72. 